\title{
Comparative analysis of the metabolically active microbial communities in the rumen of dromedary camels under different feeding systems using total rRNA sequencing
}

\author{
Alaa Rabee ${ }^{\text {Corresp., } 1}$, Robert Forster ${ }^{2}$, Chijioke Elekwachi ${ }^{2}$, Ebrahim Sabra ${ }^{3}$, Mebarek Lamara ${ }^{4}$ \\ ${ }^{1}$ Animal and Poultry nutrition department, Desert Research Center, Cairo, Cairo, Egypt \\ 2 Lethbridge Research and Development Centre, Agriculture and Agrifood Canada, Lethbridge, Alberta, Canada \\ ${ }^{3}$ Genetic Engineering and Biotechnology Research Institute, University of Sadat City, Sadat City, Menoufia, Egypt \\ 4 Institut de Recherche sur les Forêts, Université du Québec en Abitibi-Témiscamingue, Rouyn-Noranda, Québec, Canada \\ Corresponding Author: Alaa Rabee \\ Email address: alaa.bakr.stu@gebri.usc.edu.eg
}

Breakdown of plant biomass in rumen depends on interactions between bacteria, archaea, fungi, and protozoa; however, the majority of studies of the microbiome of ruminants, including the few studies of the rumen of camels, only studied one of these microbial groups. In this study, we applied total rRNA sequencing to identify active microbial communities in twenty-two solid and liquid rumen samples from eleven camels. These camels were reared at three stations that use different feeding systems: clover, hay and wheat straw (G1), fresh clover (G2), and wheat straw (G3). Bacteria dominated the libraries of sequence reads generated from all rumen samples, followed by protozoa, archaea, and fungi respectively. Firmicutes, Thermoplasmatales, Diplodinium, and Neocallimastix dominated bacterial, archaeal, protozoal and fungal communities, respectively in all samples. Libraries generated from camels reared at facility G2, where they were fed fresh clover, showed the highest alpha diversity. Principal co-ordinate analysis and linear discriminate analysis showed clusters associated with facility/feed and the relative abundance of microbes varied between liquid and solid fractions. This provides preliminary evidence that bacteria dominate the microbial communities of the camel rumen and these communities varies between populations of domesticated camels. 


\section{Comparative analysis of the metabolically active microbial}

3 communities in the rumen of dromedary camels under

4 different feeding systems using total rRNA sequencing

5

6

7

8

9

10

11
Alaa. M.E. Rabee ${ }^{1}$, Robert. J. Forster ${ }^{2}$, Chijioke. O. Elekwachi², Ebrahim.Sabra ${ }^{3}$, Mebarek. Lamara $^{4}$

${ }^{1}$ Animal and Poultry Nutrition Department, Desert Research Center, Cairo, Egypt.

${ }^{2}$ Lethbridg Research and Development Center, Agriculture and Agrifood Canada, Lethbridge, Alberta, Canada .

${ }^{3}$ Genetic Engineering and Biotechnology Research Institute, University of Sadat City, Sadat City, Menoufia, Egypt.

${ }^{4}$ Institut de Recherche sur les Forêts, Université du Québec en Abitibi-Témiscamingue, RouynNoranda, Canada.

Corresponding Author:

Alaa Rabee

Animal and Poultry Nutrition Department, Desert Research Center

1Mathaf El Matariya St.B.O.P.11753

Matariya, Cairo, Egypt

Email: rabee a m@yahoo.com

Phone: +20226332846; fax: +20226357858 


\section{Abstract}

38 Breakdown of plant biomass in rumen depends on interactions between bacteria, archaea, fungi,

39

40

41

42

43

44

45

46

47

48

49

50

51

52

53

54

55

56

57

58

59

60

61

62

63

64

65

66

67

68

69

70

71

72

73

74

75 and protozoa; however, the majority of studies of the microbiome of ruminants, including the few studies of the rumen of camels, only studied one of these microbial groups. In this study, we applied total rRNA sequencing to identify active microbial communities in twenty-two solid and liquid rumen samples from eleven camels. These camels were reared at three stations that use different feeding systems: clover, hay and wheat straw (G1), fresh clover (G2), and wheat straw (G3). Bacteria dominated the libraries of sequence reads generated from all rumen samples, followed by protozoa, archaea, and fungi respectively. Firmicutes, Thermoplasmatales, Diplodinium, and Neocallimastix dominated bacterial, archaeal, protozoal and fungal communities, respectively in all samples. Libraries generated from camels reared at facility G2, where they were fed fresh clover, showed the highest alpha diversity. Principal co-ordinate analysis and linear discriminate analysis showed clusters associated with facility/feed and the relative abundance of microbes varied between liquid and solid fractions. This provides preliminary evidence that bacteria dominate the microbial communities of the camel rumen and these communities variy between populations of domesticated camels.

\section{Introduction}

Camels (Camelus dromedaries) can produce milk and meat in hot, arid and semi-arid regions and can provide food security as the climate warms (Samsudin et al., 2011; Faye, 2013). Camels also provide textiles (fiber and hair) and are commonly used for transportation, agriculture, tourism, race and riding (Rabee et al., 2019). The unique feeding behavior and the functional structure of digestive tract of these pseudo-ruminants is well adapted to deserts (Kay et al., 1989). The retention time of feed particles in the camel forestomach is longer than other true ruminants, which prolongs the exposure of plant biomasses to the symbiotic microorganisms. This long retention improves the efficiency of digestion (Lechner-Dolland and Engelhardt, 1989). The feed ranchers provide camels, which ranges from forage in traditional pastures to concentrated supplements in intensive feedlots, influences the structure of the camel microbiome (Faye, 2013; Henderson et al. 2015).

The chemical composition of diet shapes fermentation in rumen. For instance, cellulolytic and hemicellulytic diets favor the fibrolytic microorganisms; while, starch and sugars favor the amylolytic (Carberry et al., 2012). Also, the microbial composition and diversity varies between liquid and solid rumen fractions, which might indicate different roles in rumen fermentation; for instance, plant-adherent microbiota might have a major role in fiber degradation (Ren et al., 2020).

Digestion in the camels depends on microbial fermentation in rumen (Samsudin et al., 2011) and the efficiency of this microbial fermentations is based on the interactions between a wide variety of microbial groups, including bacteria, archaea, fungi and protozoa (Yanagita et al., 2000; Kamra, 2005). Analysis of these microbial communities could lead to increases in animal productivity and reduction of greenhouse gas emissions (Henderson et al., 2015). Unlike other ruminants, camels can utilize thorny and low quality plants like shrubs with high lignocelulolytic content (Samsudin et al., 2011). Consequently, camel rumen microbes must have the capacity to degrade such poor-

Peer) reviewing PDF | (2019:12:44048:8:0:NEW 8 Sep 2020) 
76 quality feeds (Gharechahi et al., 2015). However, the microbial community in the rumen of

77 dromedary camel received less attention than other domesticated ruminants.

78 Recent development of next generation sequencing technologies provide a rapid method of

79 microbial identification in rumen and overcome the intrinsic constraints of traditional culture-

80 based methods (Samsudin et al., 2011; Ishaq and Wright, 2014). Most of assessments of

81 microbial groups in the rumen have relied on amplicon sequencing, which target a specific

82 variable region on 16S rRNA gene (Li et al. 2016). This approach needs a wide range of primers

83 to study different microbial communities (Kittelmann et al., 2013). Therefore, Primer selection

84 and amplification conditions could bias the output (Guo et al., 2015; Li et al., 2016; Elekwachi et

85 al., 2017).

86 Total RNA sequencing (RNA-Seq) offers the advantage of specifically targeting active microbes

87 and avoids biases associated with primer selection and chimera generation in PCR (Gaidos et al.,

88 2011; Guo et al., 2015; Li et al., 2016). In addition, RNA-Seq approach is capable of identifying

89 novel microbes as it is not reliant on primers for known microbes (Li et al., 2016). High-

90 throughput metatranscriptomic sequencing provides a comprehensive understanding of

91 biological systems by characterization of different groups of organisms in the same environment

92 based on the sequencing of coding and noncoding RNA (Elekwachi et al., 2017). Total RNA-Seq

93 was applied to investigate microbial communities in many different systems including, for

94 example, human gut (Qin et al., 2012), and cow rumen (Li et al., 2016; Elekwachi et al., 2017 ).

95 Previous microbiome studies on camel rumen have characterized one or two microbial groups

96 using classical or molecular approaches. For example, the protozoal community in camel rumen

97 was studied heavily by conventional microscopic methods (Ghali et al., 2005; Baraka, 2012).

98 Regarding the anaerobic fungi, a new fungal genus, Oontomyces was isolated from the rumen of

99 Indian camel (Dagar et al., 2015), and only one study investigated whole fungal community in

100 the gut of camel (Rabee et al., 2019). Only three molecular-based studies are available on the

101 bacterial community (Samsudin et al., 2011; Bhatt et al., 2013; Gharechahi et al., 2015).

102 Furthermore, only one study classified rumen archaea (Gharechahi et al., 2015).

103 In the present study, total rRNA sequencing was applied to 1) get insight into the composition of

104 active microbiota in the rumen of camels; 2) describe the distribution of microbial groups among

105 solid and liquid rumen fractions; 3 ) assessing the heterogeneity of these microbial populations

106 within different populations of domestic camels.

107

108

109

\section{Materials and Methods}

110

111

112

113

114

115

116

\section{Rumen samples}

Rumen samples were collected from eleven adult dromedary camels reared at three stations that use different feeding systems. Camels in group G1 $(n=3)$ were housed in the Maryout Research Station, Alexendria, Egypt and were fed on Egyptian clover hay (Trifolium alexandrinum), wheat straw and concentrates feed mixture. Camels in group $\mathrm{G} 2(\mathrm{n}=6)$ were housed at the commercial farm in the Kom Hammada and fed on fresh Egyptian clover (100\% high-quality forage diet) then slaughtered in the Kom Hammada slaughterhouse, Elbehera, Egypt. Camels of group G3 (n=2) were housed at the commercial farm in Cairo area and fed on wheat straw (100\% low-quality 
117 forage diet) then were slaughtered in Pasateen slaughterhouse, Cairo, Egypt. Animals were kept 118 on these diets for at least one month before the sampling time. The proximate analysis of feeds is 119 illustrated in Supplementary table S1. Details regarding camel rumen samples in this study presented in Supplementary table S2. Rumen contents were strained immediately by two layers cheesecloth to separate the liquid and solid to form twenty-two samples, frozen using liquid nitrogen and stored at $-80^{\circ} \mathrm{C}$ before further processing (Elekwachi et al., 2017). The project was approved and all samples were collected according to the Institutional Animal Care and Use Committee, Faculty of Veterinary Medicine, University of Sadat City, Egypt (Approval number: VUSC00003).

127

128

129

130

131

132

133

134

135

136

137

138

139

140

141

142

143

144

145

146

147

148

149

150

151

152

153

154

155

156

157

158

159

\section{RNA isolation, quality and quantity estimation and sequencing}

The frozen rumen samples were ground using liquid nitrogen. About 0.5 gram of frozen fine powder was used for total RNA isolation using Trizol-Reagent protocol (Invitrogen, Carlsbad, CA), followed by RNA clean up using MEGA clear Kit (Invitrogen). Total RNA quality and quantity were estimated using an Agilent 2100 bioanalyzer (Agilent Technologies, USA) and RNA 6000 Nano kit (Agilent Technologies, USA). One hundred nanogram of total RNA was reversetranscribed into first strand cDNA and sequenced using Illumina rRNA MiSeq preparation kit (Illumina, USA) by Illumina MiSeq platform.

\section{Bioinformatic data analysis}

The generated RNA sequence reads were analysed using pipeline developed by Elekwachi et al. (2017). Briefly, the sequence quality was checked using the FastQC program v. 0.11.4 (Andrews, 2010), then Trimmomatic program v. 0.35 (Bolger et al., 2014) was used to trim adaptors, barcodes, ambiguous and low quality reads. PEAR program v. 0.9.6 (Zhang et al., 2014) was used to merge read 1 and read 2 using default options. Then after, the hidden Markov models rRNAHMM tool of the rapid analysis of multiple metagenomes with a clustering and annotation pipeline (RAMMCAP) (Li, 2009) was used to sort the reads into archaea and bacteria (16S, 23S), and eukaryote (18S, 23S) rRNA sequences. Merged sequence files were then sub-sampled as needed using MEME program v. 4.10.2 (Bailey et al., 2009). For each sample, 70,000 reads were run through the pipeline. For subsequent analysis steps, 20 000, 10 000, and 2000 sequences were used for bacteria, eukaryote and archaea, respectively. Taxonomy binning for eukaryote and archaeal SSU rRNA sequences was performed using BLASTN. The sub-sampled query sequences were searched against the SILVA SSURef-111 database using an $e$-value of $1 \mathrm{e}^{-5}$. Bacterial SSU sequences were binned into operational taxonomic units (OTUs) using the "classify. seqs" command of Mothur v. 1.33.1 program (Schloss et al., 2009). The SSURef -108 gene and the SSURef-108b taxonomy databases were used. Principal co-ordinate analysis (PCoA) using Bray Curtis dissimilarity and alpha diversity indices (Chao1, Shannon and Inverse Simpson) were evaluated by Mothur (Schloss et al., 2009) based on sub-sampling of 70,000 reads per sample according the protocol "Community Structure Analysis Based on OTU Clustering" outlined in Elekwachi et al. (2017).

\section{Statistical analyses}

Data of relative abundance of bacterial phyla, protozoal genera, fungal genera and archaea genera and order Thermoplasmatales were tested for normality and homogeneity using Shapiro-Wilk test and variables that were deemed non-normal were then arcsine transformed. Linear Discriminate Analysis (LDA) and Bray Curtis Permutational Multivariate Analysis of Variance 
160 (PERMANOVA) tests depended on the relative abundance of bacterial phyla. All the protozoal, 161 fungal and archaeal genera and the order Thermoplasmatales were used to show the differences in 162 community structure and to compare the clustering of samples. Pearson correlation analysis was used to identify correlation within and between microbial communities and the correlation scores were visualized as a heatmap. The statistical analyses were performed using the SPSS v. 20.0 software package (SPSS, 1999) and PAST (Hammer et al., 2001). Sequences were deposited to the sequence read archive (SRA) under the accession number: SRP107370.

167

168

169

170

171

172

173

174

175

176

177

178

179

180

181

182

183

184

185

186

187

188

189

190

191

192

193

194

195

196

197

198

199

200

201

202

203

\section{Results}

\section{The composition and diversity of active microbial community}

Total rRNA sequencing in twenty-two solid and liquid rumen samples from eleven camels resulted in a total of 3958591 reads with average of $359872 \pm 85366$ (mean \pm standard error (SE)) reads per animal in the solid fraction (SF) and 3386392 reads with an average of $307854 \pm 60989$ reads per animal in the liquid fraction (LF). The sequence reads of bacteria dominated the active microbial community, followed by protozoa, archaea and fungi (Table 1). Relative abundance of protozoa was higher in LF-G1 (liquid fraction of G1), while relative abundance of bacteria was higher in SF-G1 (solid fraction of G1). The highest population of archaea was observed in G2 camels. Additionally, G3 camels showed the highest relative abundance of fungi (Table 1; Supplementary Figure 1). Number of OTUs and Alpha-diversity indices, Chao1, Shannon and Inverse Simpson, were higher in the rumen of LF-G2 samples (Table 1).

\section{Bacterial community}

The composition of bacterial community varied little between groups and consisted of 12 phyla. The five most predominant phyla were Firmicutes, Bacteroidetes, Proteobacteria, Spirochaetes and Fibrobacteres, respectively (Table 2). Firmicutes dominated the bacterial community in all groups and was higher in G2 followed by G1 and G3 camels, respectively, and was also higher in SF compared to LF (Table 2). At the family level, Lachnospiraceae and Ruminococcuceae dominated the Firmicutes. In addition, six genera dominated this phylum, including Butyrivibrio, RFN8YE57, Ruminococcus, vadinHA42, Acetitomaculum and Blautia (Fig. 1a and Supplementary Table S3). The second largest phylum, Bacteroidetes, showed the highest relative abundance in G3 followed by G1 and G2 camels and was higher in LF than SF (Fig. 1a and Supplementary Table S3). At the family level, Prevotellaceae, BS11_ gut group, and Rikenellaceae dominated the Bacteroidetes; and at the genus level, Prevotella, RC9_gut_group dominated the Bacteroidetes. Proteobacteria, phylum showed a higher relative abundance in LF-G1 samples and was dominated by Succinivibrionaceae family and Desulfovibrio genus (Table 2, Fig. 1a, Supplementary Table S3). The Spirochaetes phylum was higher in the SF-G3 and it was classified into two families including Spirochaetaceae and PL-11B10 and was dominated by Treponema genus. Fibrobacteres phylum was higher in SF-G3 (Table 2, Fig. 1a, Supplementary Table S3). Actinobacteria were higher in SF-G2 samples, Tenricutes phylum was higher in LF-G1 samples and Lentisphaerae phylum, was about 3-fold higher in LF as relative to SF and accounted for a large population in the camels of G3 (Table 2). Additionally, several minor bacterial phyla were also observed in the rumen of camels such as Verrucomicrobia, Elusimicrobia, Cyanobacteria and Chloroflexi (Table 2).

Of the 74 genera observed, only seven were observed exclusively in libraries generated from a specific facility, including uncultured Marinilabiaceae (Bacteroidetes), Quinella (Firmicutes) and Streptococcus (Firmicutes) that were observed only in G2 and G3 camels. Ruminobacter 
204 (Proteobacteria) was observed only in G1 and G2 camels. On the other hand, Arcobacter and 205 Succinivibrio within phylum Proteobacteria were observed only in G1 camels and 206 Betaproteobacteria (Proteobacteria) was observed only in G3 camels. Moreover, many 207 unclassified bacteria were observed across samples and accounted for $39 \%$ of total bacterial reads. 208 Most of these unclassified bacterial reads were observed in phylum Firmicutes and Bacteroidetes.

209

210

211

212

213

214

215

216

217

218

219

220

221

222

223

224

225

226

227

228

229

230

231

232

233

234

235

236

237

238

239

240

241

242

243

244

\section{Archaeal community}

Reads that classified as archaea were further classified to three orders within the phylum Euryacheota: Thermoplasmatales, Methanobacteriale and Methanomicrobial. Thermoplasmatales dominated the archaeal community and showed the highest population in LF-G3 samples, this order was not classified out of order level (Table 3, Fig. 1b). Reads that classified in the Methanobacteriale were further classified to family Methanobacteriacea that includes three genera: Methanobrevibacter, Methanophera and Methanobacterium. Methanobrevibacter is the second largest contributor in archaeal population and was higher in SF-G1 samples. Methanosphaera exhibited higher relative abundance in SF-G2 samples. Methanobacterium was absent in G3 camels; however, a small proportion of this genus was found in the camels of G1 and G2. Methanomicrobium genus, which belongs to order Methanomicrobiales and family Methanomicrobiaceae was the least contributor in archaeal population and was more prevalent in LF-G3 samples (Table 3, Fig. 1b).

\section{Protozoal community}

Reads that classified as protozoa were further classified to two families: Ophryoscolecidae and Isotrichidae (Table 4). Reads that classified in the Ophryoscolecidae were further classified to seven genera, Diplodinium, Ophryoscolex, Entodinium, Polyplastron, Eudiplodinium, Epidinium and Trichostomatia. Reads that classified in the Isotrichidae were further classified to two genera, Dasytricha and Isotricha. The variation among the camels in protozoal population was clearly observed and seemed to be higher than other microbial communities; however, the protozoal community composition was similar among the camels (Table 4, Fig. 1c). The most dominant protozoal genera were Diplodinium, Ophryoscolex and Entodinium. Camels in G1 had the highest population of Entodinium and Epidinium. Camels in G2 had the greatest population of Eudiplodinium, Ophryoscolex, Isotricha and Dasytricha and camels in G3 had the greatest population of Diplodinium, Polyplastron and Trichostomatia. On the sample fraction level, solid fraction had a higher representation of Ophryoscolex, Polyplastron, Eudiplodinium, Epidinium and Diplodinium, while liquid fraction had a higher representation of Entodinium, Isotricha and Dasytricha (Table 4, Fig. 1c).

\section{Anaerobic rumen fungal community}

Reads that classified as rumen fungi were further classified to two phyla: Neocallimastigomycota and Chytridiomycota. Reads that classified in the Neocallimastigomycota were further classified to family Neocallimasticeceae that includes three genera, Neocallimastix, Piromyces and Cyllamyces. Neocallimastix dominated the fungal community, followed by Piromyces and Cyllamyces (Table 5, Fig. 1d). These anaerobic fungal genera represented $>99.5 \%$ of the fungal population. In addition, reads that classified in the Chytridiomycota were further classified to family Spizellomycetaceae that includes genus Spizellomyces, which was noted in a very small

Peer) reviewing PDF | (2019:12:44048:8:0:NEW 8 Sep 2020) 
245 proportion $(<0.5 \%$ ) (Table 5). Neocallimastix was more abundant in the SF-G1 samples while 246 Piromyces and Cyllamyces were more abundant in LF-G2 and SF-G3 respectively (Table 5, Fig. 247 1d).

\section{Effect of feeding system and facility on the composition of microbial communities}

249

250

251

252

253

254

255

256

257

258

259

260

261

262

263

264

265

266

267

268

269

270

271

272

273

274

275

276

277

278

279

280

281

282

283

284

285

286

Multivariate analysis separated libraries by feeding system and housing facility distinctly (Figs. 2 and 3). Also, bacteria, dominated by Firmicutes, drove differences between animals (Fig. 3). Furthermore, Entodinium, Thermoplasmatales, Neocallimastix drove differences in protozoal, archaeal and fungal communities, respectively. PERMANOVA analysis revealed that the difference between camel groups was significant $(P<0.01)$ in all microbial groups (Supplementary Table S4). Pairwise comparison between camel groups based on Bonferronicorrected $\mathrm{p}$-value demonstrated that the difference was significant $(P<0.05)$ between camels of G2 and G3 in bacterial and archaeal communities (Supplementary Table S4). Moreover, the difference was significant between the three groups in the protozoal community $(P<0.05)$, whereas, in the fungal community, the difference was significant only between camels in group G1 and G2 (Supplementary Table S4).

\section{Pearson correlation between microbes in the rumen of dromedary camel}

Pearson correlation analysis (Fig. 4A, 4B), revealed many significant positive and negative correlations $(P<0.05)$. For example, in active bacteria, Bacteroidetes correlated positively with Cyllamyces and negatively with Butyrivibrio, Methanosphaera and Trichostomatia. Prevotellaceae correlated positively with Neocallimastix and Entodinium and negatively with Ruminococcaceae, Methanosphaera and Diplodinium. Fibrobacteres correlated positively with Cyllamyces, Methanomicrobium, Thermoplasmatales and Diplodinium and negatively with Methanosphaera, Epidinium, Ruminococcaceae and Butyrivibrio. Firmicutes correlated positively with Methanosphaera and negatively with Piromyces, Thermoplasmatales and Methanomicrobium.

In active archaea, Thermoplasmatales correlated positively with Diplodinium and negatively with Methanobrevibacter and Methanosphaera. In active protozoa, there was a negative correlation between Polyplastron, Entodinium, Ophryoscolex and Epidinium. In active fungi, a negative correlation was observed between Cyllamyces, Neocallimastix and Piromyces and between Piromyces and Entodinium.

\section{Discussion}

Rumen microbes can ferment a wide variety of feed components, including cellulose, xylan, amylose and protein and produce volatile fatty acids that provide the animal with approximately $70 \%$ of daily energy requirements (Bergman, 1990; Henderson et al., 2015). Furthermore, rumen fermentation generates methane, which contributes to global warming and represents $2-12 \%$ loss of feed energy for the animal (Johnson and Ward, 1996; Carberry et al., 2012; Jami et al., 2014). Investigation of these microbial communities could improve our understanding of their function in fiber digestion and lead to practices that maximize the efficiency of ruminal fermentation and minimize greenhouse gas release (Lee et al., 2012).

In this study, camel groups were fed different diets and reared in different locations. The diversity and relative abundance of microbial communities varied between camel groups, which was

Peer] reviewing PDF | (2019:12:44048:8:0:NEW 8 Sep 2020) 
287

288

289

290

291

292

293

294

295

296

297

298

299

300

301

302

303

304

305

306

307

308

309

310

311

312

313

314

315

316

317

318

319

320

321

322

323

324

325

326

327

328

329

330

supported by the results of PCoA, LDA and PERMANOVA analyses. This result agrees with the results of studies of other ruminants (Henderson et al., 2015). Camels in the present study were fed on different forages; Egyptian clover and wheat straw (Supplementary Table S1). Egyptian clover is the most balanced and nutritious fodder widely used for feeding camels (Carberry et al., 2012; Bakheit, 2013; Shrivastava et al., 2014), which might supported the high microbial diversity in G2 camels compared to other groups (Table 1). This was consistent with previous studies on cows (Pitta et al., 2010; Shanks et al., 2011; Kumar et al., 2015). Highly degradable carbohydrates support bacterial and protozoal growth (Dijkstra and Tamminga, 1995; Kumar et al., 2015), which could demonstrate their higher population in G1 camels. Additionally, higher bacterial population slows the fungi growth (Stewart et al., 1992; Orpin and Joblin, 1997), which was illustrated by low fungal population in $\mathrm{G} 1$ camels.

\section{Bacterial community}

Firmicutes phylum was more abundant than Bacteroidetes and both phyla comprised $>75 \%$ of all bacterial reads (Table 2), which agrees with studies on camels (Samsudin et al., 2011), Surti Buffalo (Pandya et al., 2010) and muskoxen (Salgado-Flores et al., 2016). The majority of Firmicutes' members have a potential role in fiber digestion, which might illustrate their higher population in G2 camels that were fed on high-quality forage and also in solid fraction. The high proportion of Ruminococcaceae and Lachnospiraceae supports this speculation (Pitta et al., 2014a; Nathani et al., 2015). Blautia and Acetitomaculum genera have a key role as reductive acetogens (Le Van et al., 1998; Yang et al., 2016) and varied among the camel groups in this study. This supports the observation that manipulation of diet can enhance reductive acetogenesis in rumen and minimize methanogenesis (Le Van et al., 1998).

Bacteroidetes were higher in samples collected from animals reared in the station that used lowquality feed (G3), which was similar to results on cattle (Pitta et al., 2014b). The phylum was dominated by family Prevotellaceae, which confirms Gharechahi et al. (2015). Members of Bacteroidetes possess diverse enzymes that can target cellulose, pectin and soluble polysaccharides released in the liquid phase (Mackenzie et al., 2015). Additionally, Prevotella genus produces propionate that is used for energy by the host (Nathani et al., 2015). We speculate that Bacteroidetes species contribute to the adaptation of camels to arid conditions.

The RC9_gut_group found in this study belongs to uncultured genera and was found also in the Rhinoceros hindgut (Bian et al., 2013). Unclassified Bacteroidetes specialize in lignocellulose degradation (Mackenzie et al., 2015), which could support their high proportion in G3 camels. Fibrobacteres was higher $(3.1 \%)$ in this study compared to the other findings on camels (Gharechahi et al., 2015); this phylum is the principal cellulolytic bacteria in the rumen (RansomJones et al., 2012; Nathani et al., 2015), which might illustrate its higher relative abundance in solid fraction and in the rumen of G3 camels that fed on wheat straw (Table 2). The members of Proteobacteria were lower in G2 and G3 camels that were fed on diet rich in fiber contents. These findings highlighted this phylum's function as a protein-degrading bacteria (Liu et al., 2017). The abundance of Treponema was higher in the solid fraction and in G3 camels (Figure 1a). Treponema is the dominant genus in Spirochaetes phylum and it is fiber-associated bacteria, which could indicate to its cellulytic and xylanolytic activities (Ishaq and Wright, 2012).

The dominant bacterial genera in this study were Butyriovibrio, RFN8-YE57, Ruminococcus, Prevotella, Fibrobacter, Treponema and VadinHA. These genera were higher in the SF except RFN8-YE57 compared to the LF; this finding was consistent with a study on camels (Gharechahi

Peer) reviewing PDF | (2019:12:44048:8:0:NEW 8 Sep 2020) 
331

332

333

334

335

336

337

338

339

340

341

342

343

344

345

346

347

348

349

350

351

352

353

354

355

356

357

358

359

360

361

362

363

364

365

366

367

368

369

370

371

372 et al., 2015), and confirms that solid-attached microbes could play a major role in ruminal fiber digestion (Jewell et al., 2015; Noel et al., 2017).

Most of Elusimicrobia in this study

Most of Elusimicrobia observed in this study have yet to be cultured; some members of this phylum were isolated from the termite's gut that degrades cellulose (Herlemann et al., 2009). Therefore, we speculate that this phylum has a role in fiber digestion and that might illustrate their high proportion in G3 camels. Actinobacteria observed also in the rumen of moose and some members of this phylum have acetogenic activities (Ishaq et al., 2015). Some members of Victivallis within Lentisphaerae phylum were involved in cellobiose degradation (Zoetendal et al., 2003).

Unclassified bacteria in our study (39\% of total bacterial reads) were less than the percentage found in a study of muskoxen (54\%) (Salgado-Flores et al., 2016). The presence of unclassified bacteria in the gut was commonly observed (Gruninger et al., 2016) and could be a result of the presence of new bacteria that ferment plant biomass (Salgado-Flores et al., 2016) or related to short reads were generated from RNA sequencing ( $\mathrm{Li}$ et al., 2016).

\section{Archaeal community}

Since some archaea produce $\mathrm{CH}_{4}$ from $\mathrm{H}_{2}$ and $\mathrm{CO}_{2}$, this phyla may control methane emission from ruminants (Hook et al., 2010). Additionally, acetate produced in fiber breakdown provides a methyl group for methanogenesis; therefore, alteration of diet shifts the structure of methanogen populations (Hook et al., 2010; Tapio et al., 2017), which could demonstrate the variation in the relative abundance of archaea between camel groups. Camels of the second group (G2) that were fed fresh clover, showed the highest archaeal population (Table 2) and archaeal community was dominated by Thermoplasmatales, a methylotrophic methanogens order (Table 3), which was consistent with the results on cattle (Carberry et al., 2014) and camels (Gharechahi et al., 2015). Thermoplasmatales produce methane from methyl amine and supplementing of animal's diet with rapeseed oil decreases the abundance of this order, making it a high potential target in future strategies to mitigate methane emissions (Poulsen et al., 2013). The Methanobrevibacter, Methanosphaera, Methanomicrobium and Methanobacterium (Table 4) dominated the reads classified as archaea in this study, which agrees with trends reported for beef cattle (Carberry et al., 2014). Methanobrevibacter dominated the methanogens in other ruminant (Henderson et al., 2015) and was associated with high methane emissions (Tapio et al., 2017). Moreover, Methanomicrobium was higher in the camels of G3 that were fed on poor quality forage, which was similar to results of buffalo (Franzolin and Wright, 2016), and in vitro (Wang et al., 2018). In rumen, Methanomicrobium converts $\mathrm{H}_{2}$ and/or formate into $\mathrm{CH}_{4}$ (Leahy et al., 2013). The abundance of Thermoplasmatales was also negatively correlated with Methanobrevibacter, which is consistent with previous results (Danielsson et al., 2017; McGovern et al., 2017).

\section{Protozoal community}

The majority of protozoal reads were classified as Diplodinium, Ophryoscolex, Entodinium, Polyplastron, Eudiplodinium and Epidinium (Table 4). Similar findings were observed on different ruminants (Baraka, 2012). Feed appeared to influence the relative abundance of protozoa, as reported previously for cattle (Hristov et al., 2001; Weimer, 2015); however, we cannot differentiate the effects of feed from facility. Diplodinium dominated protozoal community and was prevalent in G3 camels, which highlighted the cellulolytic activity of this genus (Coleman et

Peer] reviewing PDF | (2019:12:44048:8:0:NEW 8 Sep 2020) 
373 al., 1976). Some species of genus Diplodinium, such as Diplodinium cameli, were discovered in, 374 and are unique to, the rumen of Egyptian camel (Kubesy and Dehority, 2002). In addition, 375 Entodinium was higher in G1 camels that were fed on concentrates feed mixture that increase the 376 protozoa. Also, this genus predominates rumen of camels (Selim et al., 1999; Ghali et al., 2005) 377 and cattle (Carberry et al., 2012). Moreover, Kittelmann and Janssen (2011) showed that the 378 Polyplastron was the dominant genus in cattle. On the function level, all the genus Eudiplidinum, 379 Epidinum and Diplodinum have cellulolytic activity (Coleman et al., 1976), whereas, 380 Polyplastrone and Epidinium have a xylanolytic activity (Devillard, 1999; Béra-Maillet et al., 381 2005).

382

383

384

385

386

387

388

389

390

391

392

393

394

395

396

397

398

399

400

401

402

403

404

405

406

407

408

409

410

411

412

413

414

415

\section{Anaerobic rumen fungal community}

The highest fungal population was observed in the solid fraction and rumen of G3 camels (Table 1). These findings were in agreement with the results of studies stated that the fibre-based diets stimulated the fungal growth (Orpin, 1977; Roger et al., 1993; Kamra et al., 2005; Haitjema et al., 2014). This could explain the low fungal population in G1 camels in our study. Moreover, the longer retention time and neutral $\mathrm{pH}$ in camel's forestomach (Russell and Wilson, 1996) make it more suitable for the survival of rumen fungi. Neocallimastix dominated the fungal community and was higher in the G1 camels, which was similar to other results on sheep and camels (Kittelmann et al., 2013, Rabee et al., 2019). This genus produces enzymes capable of hydrolyzing cellulose, xylan and starch (Pearce and Bauchop, 1985). Cyllamyces that was observed in small population, has the ability to degrade poor-quality feeds (Sridhar et al., 2014), which might explain its high population in solid fraction and G3 camels. Piromyces was the second dominant genus in the camel rumen of this study and produces cellulolytic and xylanolytic enzymes (Teunissen et al., 1992). Therefore, this genus was most abundant in rumen collected from the G2 group of camels. The genus Spizellomyces is closely related to Chytridiomctes (Bowman et al., 1992), and common in grassland and crop soil (Lozupone and Klein, 2002, Kittelmann et al., 2012). Thus, contamination of forages by soil could explain the presence of this fungus in camel rumen.

\section{Correlation between rumen microbes}

Interactions between rumen microbes drive feed degradation and methane formation in the rumen, which influence the animal production and the environment (Williams et al., 1994; Lee et al., 2012; Henderson et al., 2015). Positive and negative correlations were observed within and between microbial communities in this study (Fig. 4). Methanogens colonize protozoa and this relationship enhances methane formation (Newbold et al., 1995). Additionally, fibrolytic bacteria produce hydrogen and methyl groups that methanogens use for growth (Johnson and Johnson, 1995), which demonstrated positive correlations found between Fibrobacteres and some methanogens. Also, positive correlation between methylotrophic Methanosphaera and Lachnospiraceae that has been implicated in pectin degradation and provides methanol as a substrate for the methylotrophs (Dehority, 1969). On the other hand, Prevotella is a hydrogen utilizer and produces propionate that impact the methanogenesis in the rumen negatively (Pitta et al., 2014a; Liu et al., 2017), which illustrates negative correlation between Prevotellaceae and archaea.

Since the rumen anaerobic fungi produce abundant $\mathrm{H}_{2}$ through the fermentation of carbohydrate; they can interact positively with $\mathrm{H}_{2}$ utilizers such as archaea, Prevotellaceae, Blautia and Acetitomaculum (Orpin and Joblin, 1997; Le Van et al., 1998; Yang et al., 2016; Liu et al., 2017). Additionally, anaerobic fungi penetrate plant tissue, providing an increased surface area for 
416 bacterial colonization (Orpin and Joblin, 1997), which could explain positive correlation between 417 fungi and both Butyrivibrio and Fibrobacteres. However, some bacteria and protozoa prey on 418 fungal zoospores (Morgavi et al., 1994), which demonstrated the negative correlation between 419 both Neocallimastix and Piromyces with Diplodinium and Entodinium. Furthermore, 420 Ruminococcus produces compounds that inhibit the growth of rumen fungi (Stewart et al., 1992), 421 which supports the negative correlation between Neocallimastix and Ruminococcaceae. 422 Polyplastron predates upon other protozoa like Epidinium, Eudiplodinium, Diplodinium, and 423 Ostracodinium (Eadie, 1967).

424

425

426

427

428

429

430

431

432

433

434

435

436

437

438

439

440

441

442

443

444

445

446

447

448

449

450

451

452

453

454

455

\section{Conclusions}

The microbial community in camel rumen was diverse and similar in composition between the groups of camels. The majority of camel rumen microbes (bacteria, fungi, and protozoa) were fibrolytic or have a possible role in fiber digestion, which might illustrate the ability of camel to live in desert harsh conditions under poor feeds. Moreover, the structure of microbial community in rumen of camels was similar to other ruminants.

\section{References}

Andrews S. 2010. FastQC A Quality Control Tool for High Throughput Sequence Data.

Bakhei, BR. 2013. Egyptian clover (Trifolium alexandrinum) breeding in Egypt: A review. Asian Journal of Crop Science 5: 325-337 DOI 10.3923/ajcs.2013

Bailey TL, Boden M, Buske FA, Frith M, Grant CE, Clementi L, Ren J, Li WW, Noble WS. 2009. MEME SUITE: tools for motif discovery and searching. Nucleic Acids Research 37(Web Server issue): W202-W208 DOI 10.1093/nar/gkp335

Baraka TA. 2012. Comparative studies of rumen $\mathrm{pH}$, total protozoa count, generic and species composition of ciliates in camel, buffalo, cattle, sheep and goat in Egypt. Journal of American Science 8: 448-462.

Bergman EN. 1990. Energy contributions of volatile fatty acids from the gastrointestinal tract in various species. Physiological Reviews 70: 567-90 DOI 10.1152/physrev.1990.70.2.567.

Béra-Maillet C, Devillard E, Cezette M, Jouany J, Forano E. 2005. Xylanases and carboxymethylcellulases of the rumen protozoa Polyplastron multivesiculatum, Eudiplodinium maggii and Entodinium sp. FEMS Microbiology Letters 244: 49-156 DOI 10.1016/j.femsle.2005.01.035.

Bhatt VD, Dande SS, Patil NV, Joshi CG. 2013. Molecular analysis of the bacterial microbiome in the forestomach fluid from the dromedary camel (Camelus dromedarius). Molecular Biology Reports 40: 3363-3371 DOI 10.1007/s11033-012-2411-4.

Bian G, Ma L, Su Y, Zhu W. 2013. The microbial community in the feces of the white Rhinoceros (Ceratotherium simum) as determined by barcoded pyrosequencing analysis. PLoS One 8: e70103 DOI 10.1371/journal.pone.0070103.

Bolger AM, Lohse M, Usadel B. 2014. Trimmomatic: a flexible trimmer for Illumina sequence data. Bioinformatics 30: 2114-2120 DOI 10.1093/bioinformatics/btu170. 
456 Bowman BH, Taylor JW, Brownlee AG, Lee J, Lu SD, White TJ. 1992. Molecular evolution of 457 the fungi: relationship of the Basidiomycetes, Ascomycetes, and Chytridiomycetes. Molecular 458 Biology and Evolution 9: 285-296 DOI 10.1093/oxfordjournals.molbev.a040720.

459 Carberry CA, Waters SM, Kenny DA, Creevey CJ. 2014. Rumen methanogenic genotypes differ 460 in abundance according to host residual feed intake phenotype and diet type. Applied and 461 Environmental Microbiology 80: 586-594 DOI 10.1128/AEM.03131-13.

462 Carberry CA, Kenny DA, Han S, McCabe MS, Waters SM .2012. Effect of phenotypic residual 463 feed intake and dietary forage content on the rumen microbial community of beef cattle. Applied 464 and Environmental Microbiology 78: 4949-4958 DOI 10.1128/AEM.07759-11.

465 Coleman GS, Laurie J I, Bailey JE, Holdgate SA. 1976. The cultivation of cellulolytic protozoa 466 isolated from the rumen. Journal of General Microbiology 95: 144-150 DOI 10.1099/00221287467 95-1-144.

468 Dagar SS, Kumar S, Griffith GW, Edwards JE, Callaghan TM, Singh R, Nagpal AK, Puniya A 469 K. 2015. A new anaerobic fungus (Oontomyces anksri gen. nov., sp. nov.) from the digestive tract of the Indian camel (Camelus dromedarius). Fungal Biology 119:731-737 DOI 10.1016/j.funbio.2015.04.005.

472 Danielsson R, Dicksved J, Sun L, Gonda H, Müller B, Schnürer A, Bertilsson J. 2017. Methane production in dairy cows correlates with rumen methanogenic and bacterial community structure. Frontiers in Microbiology 8: 226 DOI 10.3389/fmicb.2017.00226.

475 Dehority BA. 1969. Pectin-fermenting bacteria isolated from the bovine rumen. Journal of 476 Bacteriology 99: 189-196.

477 Devillard E, Newbold CJ, Scott KP, Forano E, Wallace RJ, Jouany JP, Flint HJ. 1999. A 478 xylanase produced by the rumen anaerobic protozoan Polyplastron multivesiculatum shows close 479 sequence similarity to family 11 xylanases from Gram-positive bacteria. FEMS Microbiology 480 Letters 181: 145-152 DOI 10.1111/j.1574-6968.1999.tb08837.x.

481 Dijkstra J, Tamminga S. 1995. Simulation of the effects of diet on the contribution of rumen 482 protozoa to degradation of fibre in the rumen. British Journal of Nutrition 74: 617-634 DOI 483 10.1079/BJN19950166.

484 Eadie JM. 1967. Studies on the ecology of certain rumen ciliate protozoa. Journal of General 485 Microbiology 49: 175-194 DOI 10.1099/00221287-49-2-175.

486 Elekwachi CO, Wang Z, Wu X, Rabee A, Forster RJ. 2017. Total rRNA-Seq analysis gives 487 insight into bacterial, fungal, protozoal and archaeal communities in the rumen using an 488 optimized RNA isolation method. Frontiers in Microbiology 8: 1814 DOI $48910.3389 /$ fmicb.2017.01814.

490 Faye B. 2013. Camel farming sustainability: The challenges of the camel farming system in the 491 XXIth century. Journal of Sustainable Development 6: 74-82 DOI 10.5539/jsd.v6n12p74.

492 Franzolin R, Wright AG. 2016. Microorganisms in the rumen and reticulum of buffalo (Bubalus 493 bubalis)fed two different feeding systems. BMC Research Notes 9: 243 DOI 10.1186/s13104494 016-2046-y. 
495 Gaidos E, Rusch A, Ilardo M. 2011. Ribosomal tag pyrosequencing of DNA and RNA from 496 benthic coral reef microbiota: community spatial structure, rare members and nitrogen-cycling 497 guilds. Environmental Microbiology 13: 1138-1152 DOI 10.1111/j.1462-2920.2010.02392.x.

498 Ghali MB, Scott PT, Jassim RAM. 2005. Effect of diet change on population of rumen protozoa 499 in dromedary camel. Recent Advances in Animal Nutrition in Australia. 15: 27A.

500 Gharechahi J, Zahiri HS, Noghabi KA, Salekdeh GH. 2015. In-depth diversity analysis of the 501 bacterial community resident in the camel rumen. Systematic and Applied Microbiology 38: 6750276 DOI 10.1016/j.syapm.2014.09.004.

503 Gruninger RJ, McAllister TA, Forster RJ. 2016. Bacterial and archaeal diversity in the 504 gastrointestinal tract of the orth American Beaver (Castor canadensis). PLoS ONE 11: e0156457 505 DOI 10.1371/journal.pone.0156457.

506 Guo J, Cole J, Zhang Q, Brown C, Tiedje J. 2015. Microbial community analysis with ribosomal 507 gene fragments from shotgun metagenomes. Applied and Environmental Microbiology 82: 157508166 DOI 10.1128/AEM.02772-15.

509 Haitjema CH, Solomon KV, Henske JK, Theodorou MK, O'Malley MA. 2014. Anaerobic gut 510 fungi: Advances in isolation, culture, and cellulolytic enzyme discovery for biofuel production.

511 Biotechnology and Bioengineering 111: 1471-1482 DOI 10.1002/bit.25264.

512 Hammer Ø, Harper DAT, Ryan PD. 2001. PAST: Paleontological statistics software package for 513 education and data analysis. Palaeontologia Electronica 4: 9 https://palaeo514 electronica.org/2001_1/past/issue1_01.htm.

515 Henderson G, Cox F, Ganesh S, Jonker A, Young W, Janssen PJ. 2015. Rumen microbial 516 community composition varies with diet and host, but a core microbiome is found across a wide 517 geographical range. Scientific Reports 5: 14567 DOI 10.1038/srep14567.

518 Herlemann DPR, Geissinger O, Ikeda-Ohtsubo W, Kunin V, Sun H, Lapidus A, Hugenholtz P, d 519 Brune A. 2009. Genomic analysis of "Elusimicrobium minutum," the first cultivated 520 representative of the phylum "Elusimicrobia" (formerly termite group 1). Applied and 521 Environmental Microbiology 70: 2841-2849 DOI 10.1128/AEM.02698-08.

522 Hook SE, Wright ADG, McBride BW. 2010. Methanogens: methane producers of the rumen and 523 mitigation strategies. Archaea 2010: 945785 http://dx.doi.org/10.1155/2010/945785.

524 Hristov AN, Ivan M, Rode LM, McAllister TA. 2001. Fermentation characteristics and ruminal

525

526

527

528

529

530

531

532

533

534

535 ciliate protozoal populations in cattle fed medium- or high-concentrate barley-based diets. Journal of Animal Science 79: 515-524 DOI 10.2527/2001.792515x.

Ishaq SL, Wright AG. 2012. Insight into the bacterial gut microbiome of the North American moose (Alces alces). BMC Microbiology 12: 212 DOI 10.1186/1471-2180-12-212.

Ishaq SL, Wright ADG. 2014. High-throughput DNA sequencing of the ruminal bacteria from moose (Alces alces) in Vermont, Alaska, and Norway. Microbial Ecology 68: 185-195 DOI 10.1007/s00248-014-0399-0.

Ishaq S, Sundset M, Crouse J, Wright A. 2015. High-throughput DNA sequencing of the moose rumen from different geographical locations reveals a core ruminal methanogenic archaeal diversity and a differential ciliate protozoal diversity. Microbial Genomics 1: e000034 DOI 10.1099/mgen.0.000034. 
536 Jami E, White BA, Mizrahi I. 2014. Potential role of the bovine rumen microbiome in

537 modulating milk composition and feed efficiency. PLoS ONE 9: e85423 DOI

538 10.1371/journal.pone.0085423.

539 Jewell KA, McComirck C, Odt CL, Weimer PJ, Suen G. 2015. Ruminal bacterial community

540 composition in dairy cows is dynamic over the course of two lactations and correlates with feed

541 efficiency. Applied and Environmental Microbiology 18: 4697-4710 DOI 10.1128/AEM.00720-

54215.

543 Johnson KA, Johnson DE. 1995. Methane emissions from cattle. Journal of Animal Science 73:

544 2483-2492 DOI 10.2527/1995.7382483x.

545 Johnson DE, Ward GM. 1996. Estimates of animal methane emissions. Environmental

546 Monitoring and Assessment 42: 113-141 DOI 10.1007/BF00394046.

547 Kamra DN. 2005. Rumen microbial ecosystem. Current Science 89 124-135.

548 Kay RNB, Maloiy MO. 1989. Digestive secretions in camels. Options Méditerranéennes - Série

549 Séminaires - n." 2:83-87.

550 Kittelmann S, Naylor GE, Koolaard JP, Janssen PH. 2012. A proposed taxonomy of anaerobic

551 fungi (Class Neocallimastigomycetes) suitable for large-scale sequence-based community

552 structure analysis. PLoS ONE 7: e36866 DOI 10.1371/journal.pone.0036866.

553 Kittelmann S, Seedorf H, Waters WA, Clemente JC, Knight R, Gordon J, Janssen PH. 2013.

554 Simultaneous amplicon sequencing to explore co-occurrence patterns of bacterial, archaeal and

555 eukaryotic microorganisms in rumen microbial communities. PloS ONE 8: e47879 DOI

556 10.1371/journal.pone.0047879.

557 Kittelmann S, Janssen PH. 2011. Characterization of rumen ciliate community composition in

558 domestic sheep, deer, and cattle, feeding on varying diets, by means of PCR-DGGE and clone

559 libraries. FEMS Microbiology Ecology 75: 468-481 DOI 10.1111/j.1574-6941.2010.01022.x.

560 Kubesy AA, Dehority BA. 2002. Forestomach ciliate Protozoa in Egyptian dromedary camels

561 (Camelus dromedarius). ZOOTAXA 51: 1-12.

562 Kumar S, Indugu N, Vecchiarelli B, Pitta DW. 2015. Associative patterns among anaerobic

563 fungi, methanogenic archaea, and bacterial communities in response to changes in diet and age in

564 the rumen of dairy cows. Frontiers in Microbiology 6: 781 DOI 10.3389/fmicb.2015.00781.

565 Le Van TD, Robinson JA, Ralph J, Greening RC, Smolenski WJ, Leedle JA, Schaefer DM.

566 1998. Assessment of reductive acetogenesis with indigenous ruminal bacterium populations and

567 Acetitomaculum ruminis. Applied and Environmental Microbiology 64: 3429-36.

568 Leahy S, Kelly W, Ronimus R, Wedlock N, Altermann E, Attwood G. 2013. Genome

569 sequencing of rumen bacteria and archaea and its application to methane mitigation strategies.

570 Animal 7: 235-243 DOI 10.1017/S1751731113000700.

571 Lechner-Doll M, Engelhardt WV. 1989. Particle size and passage from the forestomach in camels

572 compared to cattle and sheep fed a similar diet. Journal of Animal Physiology and Animal Nutrition

573 61:120-128 https://doi.org/10.1111/j.1439-0396.1989.tb00091.x.

574 Lee HJ, Jung JY, Oh YK, Lee SS, Madsen EL, Jeon CO. 2012. Comparative survey of rumen

575 microbial communities and metabolites across one Caprine and three Bovine groups, using bar-

Peer) reviewing PDF | (2019:12:44048:8:0:NEW 8 Sep 2020) 
576 coded pyrosequencing and ${ }^{1} \mathrm{H}$ nuclear magnetic resonance spectroscopy. Applied and

577 Environmental Microbiology 78: 5983-5993 DOI 10.1128/AEM.00104-12.

578 Li W. 2009. Analysis and comparison of very large metagenomes with fast clustering and

579 functional annotation. BMC Bioinformatics 10:359 DOI 10.1186/1471-2105-10-359.

580 Li F, Henderson G, Sun X, Cox F, Janssen PH, Guan LL. 2016. Taxonomic assessment of rumen 581 microbiota using total RNA and targeted amplicon sequencing approaches. Frontiers in

582 Microbiology 7 : 987 DOI 10.3389/fmicb.2016.00987.

583 Liu K, Xu Q, Wang L, Guo W, Zhou M. 2017. The impact of diet on the composition and 584 relative abundance of rumen microbes in goat. Asian-Australasian Journal of Animal Sciences 585 30: 531-537 DOI 10.5713/ajas.16.0353.

586 Lozupone CA, Klein DA. 2002. Molecular and cultural assessment of chytrid and Spizellomyces 587 populations in grassland soils. Mycologia 94: 411-420 DOI 10.1080/15572536.2003.11833206.

588 Mackenzie AK, Naas AE, Kracun SK, Schuckel J, Fangel JU, Agger JW, Willats WG, Eijsink 589 VG, Pope PB. 2015. A polysaccharide utilization locus from an uncultured Bacteroidetes 590 phylotype suggests ecological adaptation and substrate versatility. Applied and Environemental 591 Microbiology 81: 187-195 DOI 10.1128/AEM.02858-14.

592 McGovern E, McCabe MS, Cormican P, Popova M, Keogh K, Kelly AK, Kenny DA, Waters S 593 M. 2017. Plane of nutrition affects the phylogenetic diversity and relative abundance of 594 transcriptionally active methanogens in the bovine rumen. Scientific Reports 7: 13047 595 https://doi.org/10.1038/s41598-017-13013-y.

596 Morgavi DP, Sakurada M, Mizokami M, Tomita Y, Onodera R. 1994. Effects of ruminal 597 protozoa on cellulose degradation and the growth of an anaerobic ruminal fungus, Piromyces $s p$ 598 strain OTS1, in vitro. Applied and Environmental Microbiology 60: 3718-3723.

599 Nathani NM, Patel AK, Mootapally CS, Reddy B, Shah SV, Lunagaria PM, Kothari RK, Joshi 600 CG. 2015. Effect of roughage on rumen microbiota composition in the efficient feed converter 601 and sturdy Indian Jaffrabadi buffalo (Bubalus bubalis). BMC Genomics 16: 1116 DOI 602 10.1186/s12864-015-2340-4.

603 Newbold CJ, Lassalas B, Jouany JP. 1995. The importance of methanogens associated with 604 ciliate protozoa in ruminal methane production in vitro. Letters in Applied Microbiology 21: 605 230-234 DOI 10.1111/j.1472-765X.1995.tb01048.x.

606 Noel SJ, Attwood GT, Rakonjac J, Moon CD, Waghorn GC, Janssen PH. 2017. Seasonal 607 changes in the digesta-adherent rumen bacterial communities of dairy cattle grazing pasture. 608 PLOS ONE 12: e0173819 DOI 10.1371/journal.pone.0173819.

609 Orpin CG. 1977. The rumen flagellate Piromonas communis: its life cycle and invasion of plant 610 material in the rumen. Journal of General Microbiology 99: 107-117 DOI 10.1099/00221287611 99-1-107.

612 Orpin CG, Joblin KN. 1997. The rumen anaerobic fungi. In: The Rumen Microbial Ecosystem 613 (Hobson PN \& Stewart CS, eds), pp. 140-184. Blackie Academic and Professional, London. 
614 Pandya PR, Singh KM, Parnerkar S, Tripathi AK, Mehta HH, Rank DN, Kothari RK, Joshi CG. 615 2010. Bacterial diversity in the rumen of Indian Surti buffalo (Bubalus bubalis), assessed by 16S 616 rDNA analysis. Journal of Applied Genetics 51: 395-402 DOI 10.1007/BF03208869.

617 Pearce PD, Bauchop T. 1985. Glycosidases of the rumen anaerobic fungus Neocallimastix

618 frontalis grown on cellulosic substrates. Applied and Environmental Microbiology 49: 1265-

6191269.

620 Pitta DW, Parmar N, Patel AK, Indugu N, Kumar S, Prajapathi KB, Patel AB, Reddy B, Joshi C. 621 2014b. Bacterial diversity dynamics associated with different diets and different primer pairs in 622 the rumen of Kankrej cattle. PLoS ONE 9: e111710 DOI 10.1371/journal.pone.0111710.

623 Pitta DW, Kumar S, Veiccharelli B, Parmar N, Reddy B, Joshi CG. 2014a. Bacterial diversity 624 associated with feeding dry forage at different dietary concentrations in the rumen contents of 625 Mehshana buffalo (Bubalus bubalis) using 16S pyrotags. Anaerobe 25: 31-41 DOI

626 10.1016/j.anaerobe.2013.11.008.

627 Pitta DW, Pinchak E, Dowd SE, Osterstock J, Gontcharova V. 2010. Rumen bacterial diversity

628 dynamics associated with changing from Bermuda grass hay to grazed winter wheat diets.

629 Microbial Ecology 59: 511-522 DOI 10.1007/s00248-009-9609-6.

630 Poulsen M, Schwab C, Jensen B, Engberg R, Spang A, Canibe N, Højberg O, Milinovich G, 631 Fragner L, Schleper C, Weckwerth W, Lund P, Schramm A, Urich T. 2013. Methylotrophic 632 methanogenic Thermoplasmata implicated in reduced methane emissions from bovine rumen.

633 Nature Communications 4: 1428 DOI 10.1038/ncomms2432.

634 Qin J, Li Y, Cai Z, Li S, Zhu J, Zhang F, Liang S, Zhang W, Guan Y, Shen D, Peng Y, Zhang D, 635 Jie Z, Wu W, Qin Y, Xue W, Li J, Han L, Lu D, Wu P, Dai Y, Sun X, Li Z, Tang A, Zhong S, Li 636 X, Chen W, Xu R, Wang M, Feng Q, Gong M, Yu J, Zhang Y, Zhang M, Hansen T, Sanchez G, 637 Raes J, Falony G, Okuda S, Almeida M, LeChatelier E, Renault P, Pons N, Batto JM, Zhang Z, 638 Chen H, Yang R, Zheng W, Li S, Yang H, Wang J, Ehrlich SD, Nielsen R, Pedersen O, 639 Kristiansen K, Wang J. 2012. A metagenome wide association study of gut microbiota in type 2 640 diabetes. Nature 490: 55-60 DOI 10.5524/100036.

641 Rabee AE, Forster RJ, Elekwachi CO, Kewan KZ, Sabra EA, Shawket SM, Mahrous HA, 642 Khamiss OA. 2019. Community structure and fibrolytic activities of anaerobic rumen fungi in 643 dromedary camels. Journal of Basic Microbiology 49: 1-10 DOI 10.1002/jobm.201800323

644 Ransom-Jones E, Jones DL, McCarthy AJ, McDonald JE. 2012. The Fibrobacteres: an important 645 phylum of cellulose-degrading bacteria. Microbial Ecology 63: 267-281 DOI 10.1007/s00248646 011-9998-1.

647 Ren Q, Si H, Yan X, Liu C, Ding L, Long R, Li Z, Qiu Q. 2020. Bacterial communities in the 648 solid, liquid, dorsal, and ventral epithelium fractions of yak (Bos grunniens) rumen.

649 MicrobiologyOpen 9: e963 https://doi.org/10.1002/mbo3.963.

650 Roger V, Bernalier A, Grenet E, Fonty G, Jamot J, Gouet P. 1993. Degradation of wheat straw 651 and maize stem by a monocentric and a polycentric rumen fungus, alone or in association with 652 rumen cellulolytic bacteria. Animal Feed Science and Technology 42: 69-82 DOI 10.1016/0377653 8401(93)90024-E.

654 Russell JB, Wilson DB. 1996. Why are ruminal cellulolytic bacteria unable to digest cellulose at 655 low pH?. Journal of Dairy Science 79: 1503-1509 DOI 10.3168/jds.S0022-0302(96)76510-4. 
656 Salgado-Flores A, Bockwoldt M, Hagen L, Pope P, Sundset M. 2016. First insight into the faecal 657 microbiota of the high Arctic muskoxen (Ovibos moschatus). Microbial Genomics 2: e000066 658 DOI 10.1099/mgen.0.000066.

659 Samsudin AA, Evans PN, Wright AD, Al Jassim R. 2011. Molecular diversity of the foregut 660 bacteria community in the dromedary camel (Camelus dromedarius). Environmental 661 Microbiology 13: 3024-3035 DOI 10.1111/j.1462-2920.2011.02579.x.

662 Schloss PD, Westcott SL, Ryabin T, Hall JR, Hartmann M, Hollister EB, Lesniewski RA, 663 Oakley BB, Parks DH, Robinson CJ, Sahl JW, Stres B, Thallinger GG, Van Horn DJ, Weber C 664 F. 2009. Introducing mothur: Open-source, platform-independent, community-supported 665 software for describing and comparing microbial communities. Applied and Environmental 666 Microbiology 75: 7537-7541 DOI 10.1128/AEM.01541-09.

667 Selim HM, Imai S, ElSheik AK, Attia H, Okamot E. 1999. Rumen ciliate protozoal fauna of 668 native sheep, Friesian cattle and Dromedary camel in Libya. Journal of Veterinary Medical 669 Science 61: 303-305 DOI 10.1292/jvms.61.303.

670 Shanks OC, Kelty CA, Archibeque S, Jenkins M, Newton RJ, McLellan SL, Huse SM, Sogin M 671 L. 2011. Community structures of fecal bacteria in cattle from different animal feeding 672 operations. Applied and Environmental Microbiology 77: 2992-3001 DOI 10.1128/AEM.0298867310.

674 Shrivastava B, Jain KK, Kalra A, kuhad RC. 2014. Bioprocessing of wheat straw into 675 nutritionally rich and digested cattle feed. Scientific Reports 4: 6360 DOI 10.1038/srep06360.

676 SPSS. 1999. Statistical package for social science "Release 15, SPSS INC, Chicago. USA.

677 Sridhar M, Kumar D, Anadan S. 2014. Cyllamyces icaris sp. nov., a new anaerobic gut fungus 678 with nodular sporangiophores isolated from Indian water buffalo (Bubalus bubalis).

679 International Journal of Current Research and Academic Review 2: 7- 24.

680 Stewart CS, Duncan SH, Richardson AJ. 1992. The inhibition of fungal cellulolysis by cell-free 681 preparations from Ruminococci. FEMS Microbiology Letters 97: 83-87 DOI 10.1111/j.1574682 6968.1992.tb05444.x.

683 Tapio I, Snelling TJ, Strozzi F, Wallace RJ. 2017. The ruminal microbiome associated with 684 methane emissions from ruminant livestock. Journal of Animal Science and Biotechnology 8: 7 685 DOI 10.1186/s40104-017-0141-0.

686 Teunissen MJ, Dekort GM, Opdencamp HM, Huistveld HJ. 1992. Production of cellulolytic and 687 xylanolytic enzymes during growth of the anaerobic fungus Piromyces sp. on different 688 substrates. Journal of General Microbiology 138: 1657-1664 DOI 10.1099/00221287-138-86891657.

690 Wang K, Nan X, Chu K, Tong J, Yang L, Zheng S, Zhao G, Jiang L, Xiong B. 2018. Shifts of 691 hydrogen metabolism from methanogenesis to propionate production in response to replacement 692 of forage fiber with non-forage fiber sources in diets in vitro. Frontiers in Microbiology 9:2764 693 DOI 10.3389/fmicb.2018.02764.

694 Weimer PJ. 2015. Redundancy, resilience, and host specificity of the ruminal microbiota:

695 implications for engineering improved ruminal fermentations. Frontiers in Microbiology 6: 296 696 DOI 10.3389/fmicb.2015.00296. 
697 Williams AG, Withers SE, Naylor GE, Joblin KN. 1994. Effect of heterotrophic ruminal bacteria 698 on xylan metabolism by the anaerobic fungus Piromyces communis. Letters in Applied

699 Microbiology 19: 105-109 DOI 10.1111/j.1472-765X.1994.tb00917.x.

700 Yanagita K, Kamagata Y, Kawaharasaki M, Suzuki T, Nakamura Y, Minato H. 2000.

701 Phylogenetic analysis of methanogens in sheep rumen ecosystem and detection of

702 Methanomicrobium mobile by fluorescence in situ hybridization. Journal Bioscience,

703 Biotechnology, and Biochemistry 64: 1737-1742 DOI 10.1271/bbb.64.1737.

704 Yang CL, Mi L, Hu XL, Liu JX, Wang JK. 2016. Investigation into host selection of the cecal

705 acetogen population in rabbits after weaning. PLoS One 11: e0158768 DOI

706 10.1371/journal.pone.0158768.

707 Zhang J, Kobert K, Flouri T, Stamatakis A. 2014. PEAR: a fast and accurate Illumina Paired-End 708 read merger. Bioinformatics 30: 614-620 DOI 10.1093/bioinformatics/btt593.

709 Zoetendal E, Plugge CM, Akkermans ADL, Vos WM. 2003. Victivallisvadensis gen. nov., sp. 710 nov., a sugar-fermenting anaerobe from human faeces. International Journal of Systematic and 711 Evolutionary Microbiology 53: 211-215 DOI 10.1099/ijs.0.02362-0. 


\section{Figure 1}

The relative abundance of microbial groups

Figure 1: Comparison of relative abundance of genera of the microbiota in dromedary camel. bacterial (a), archaeal (b), protozoal (c) and fungi (d) in ruminal solid (SF) and liquid (LF) fractions of camels under different feeding systems. 

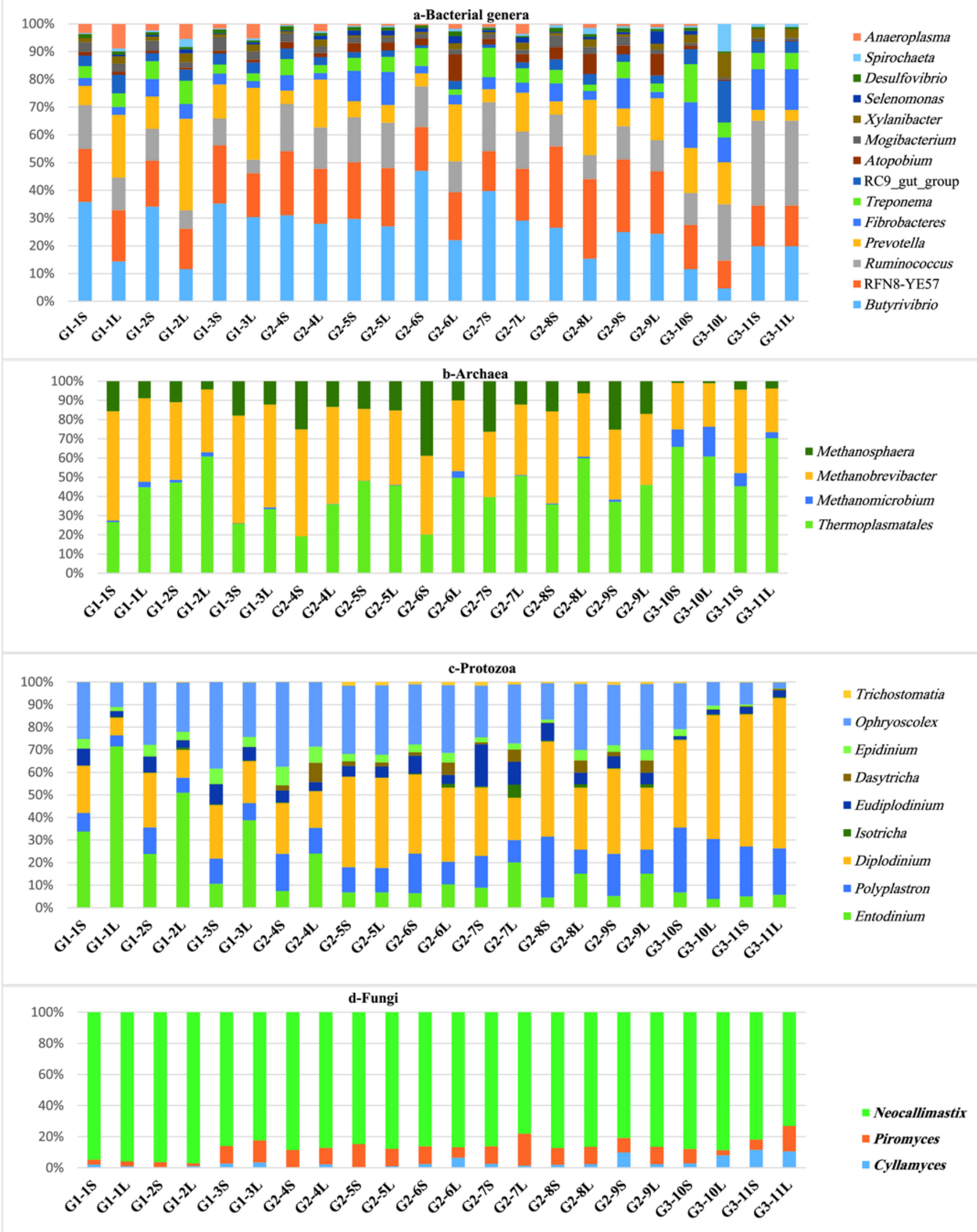
Figure 2

Principal Co-ordinated analysis

Figure 2: Principal Co-ordinated analysis derived from OTUs from twenty-two ruminal liquid (LF) and solid (SF) samples distributed on three camel groups. G1 camels (red circles), G2 (white circle and G3(blue circles). 


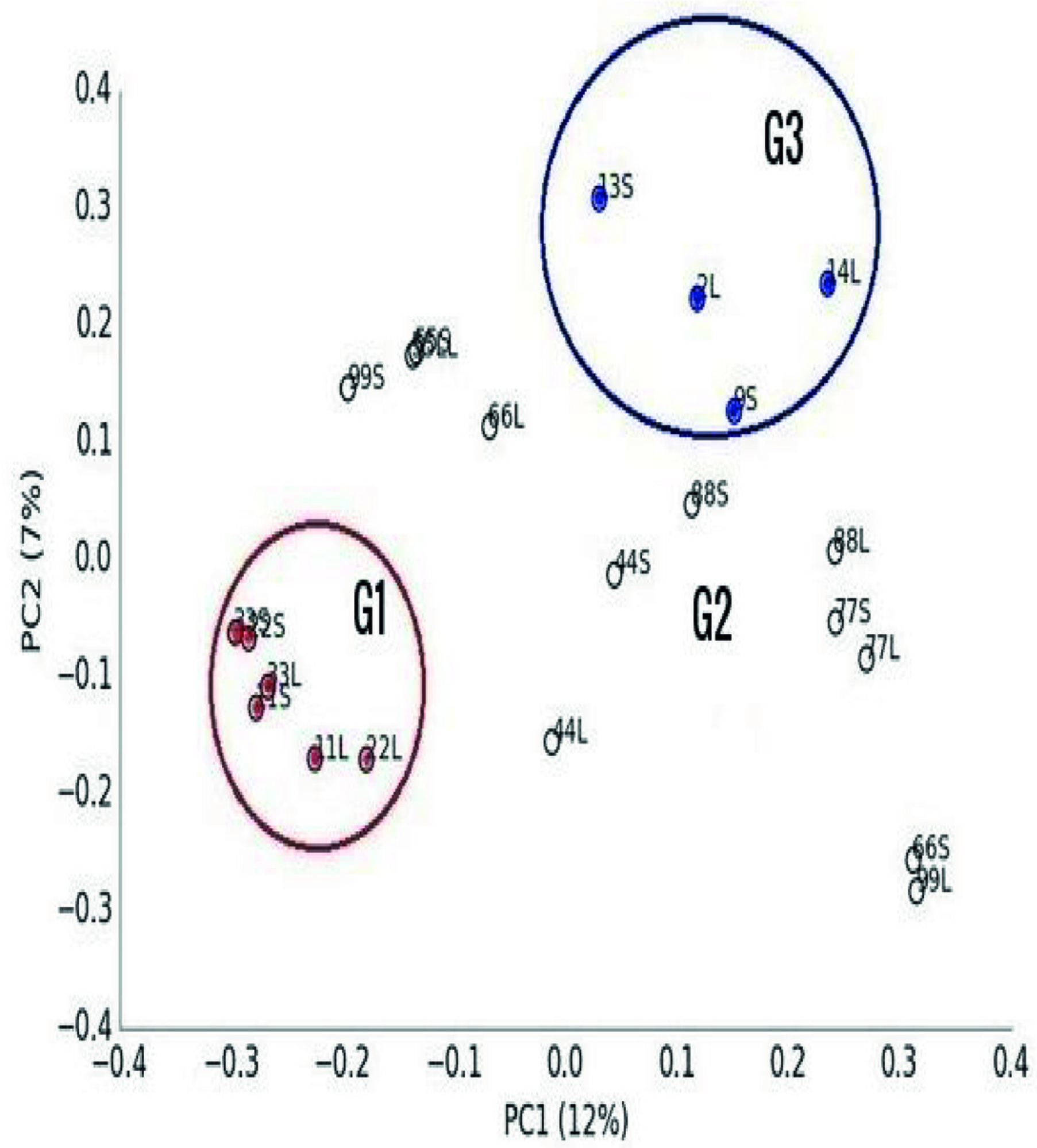


Figure 3

Linear Discriminant analysis

Figure 3:Linear Discriminant analysis of microbial communities in the samples based on the relative abundance of genera of active bacteria (a), archaea (b), protozoa (c) and fungi i (d) in ruminal solid (SF), and liquid (LF) fractions of camels under three feeding systems, G1 (black dots), G2 (blue squares) and G3 (coral triangles). 
a-Bacteria

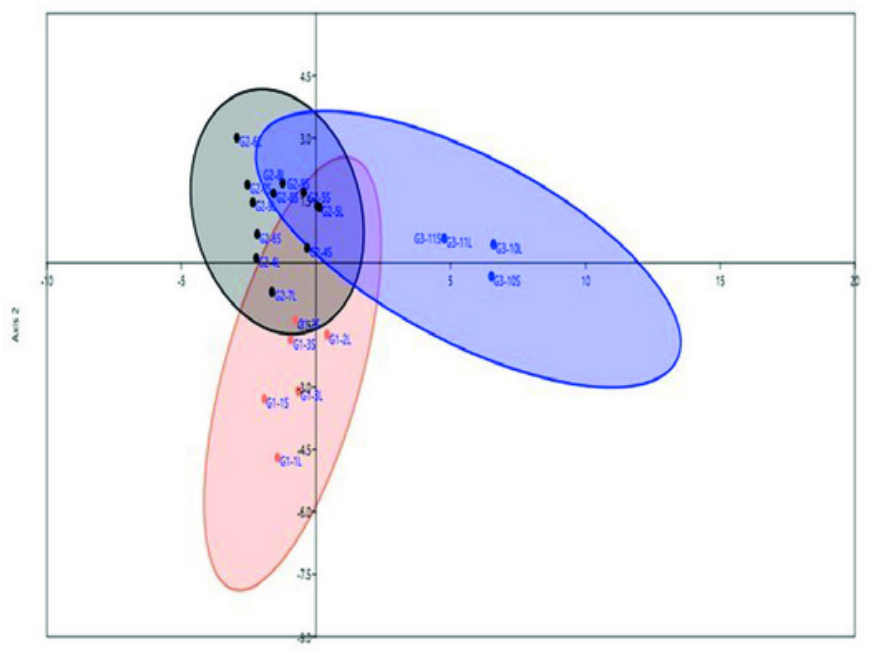

ast

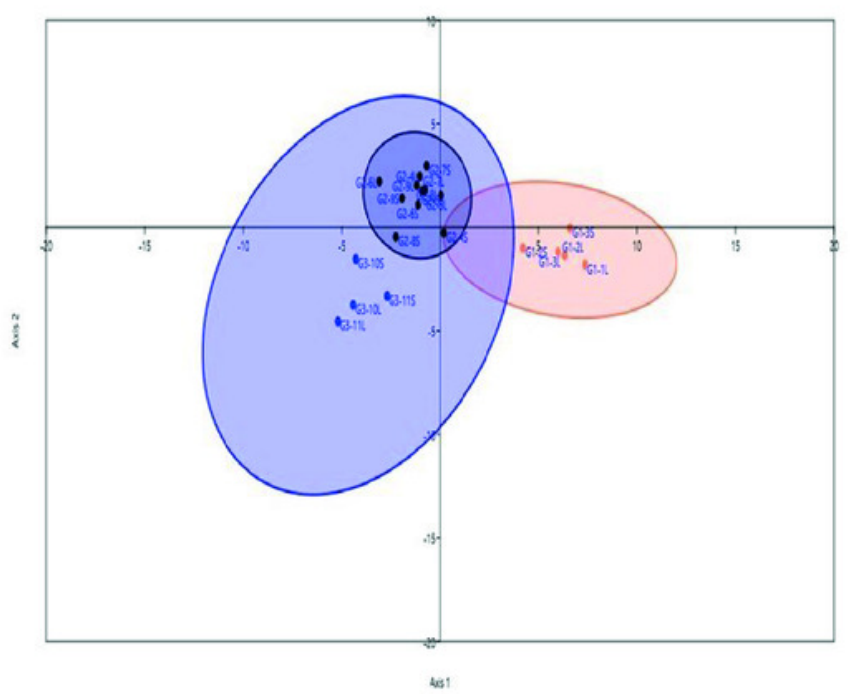

\section{B-Archaea}

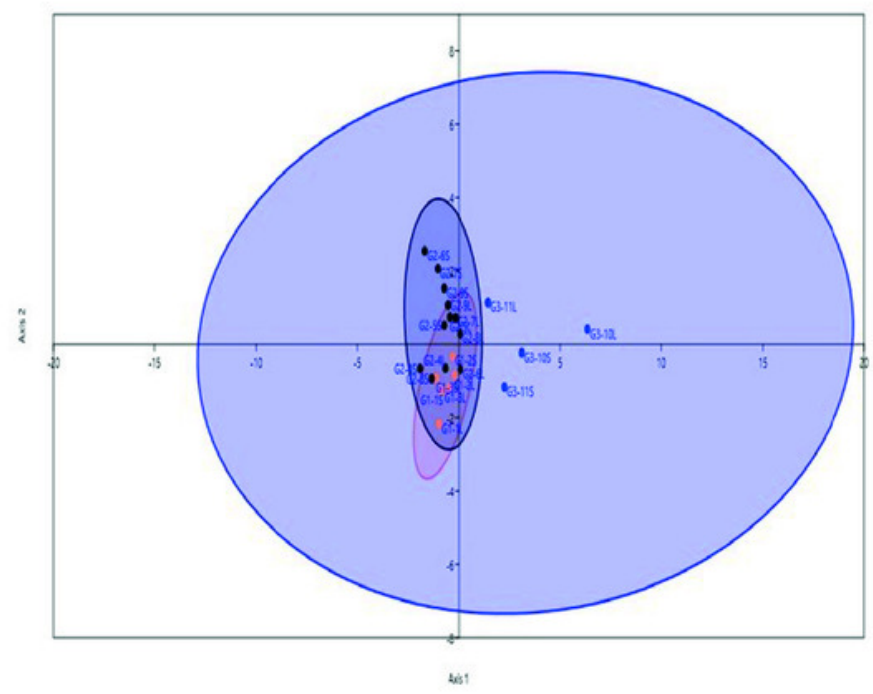

\section{d-Fungi}

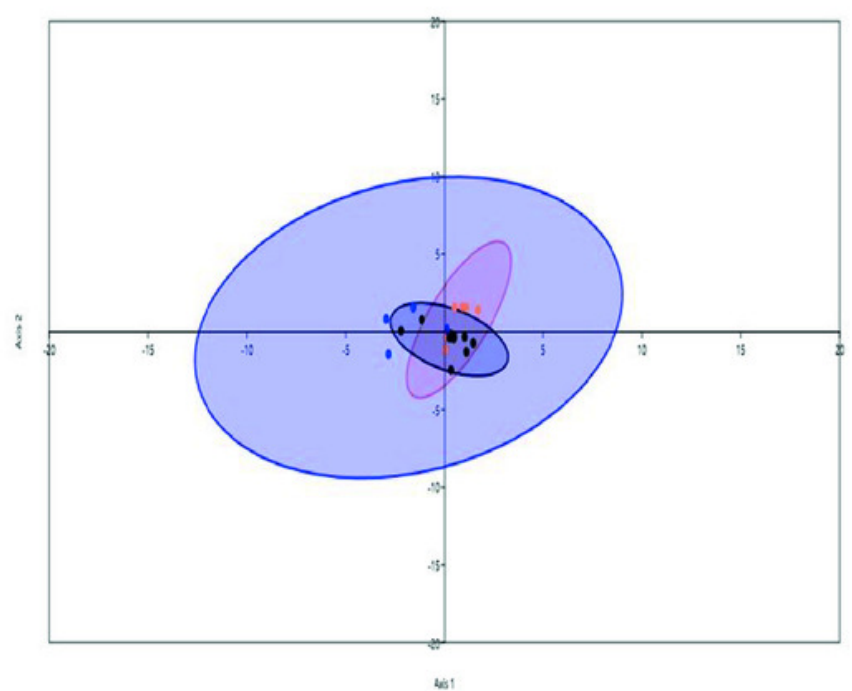


Figure 4

Heatmap based on Pearson correlation

Figure 4: Heatmap based on Pearson correlation coefficients between and within the relative abundance of bacteria, archaea, protozoa and fungi in solid (A) and liquid (B) rumen fractions of dromedary camel. The black boxed ellipses refer to the significant correlations at $\mathrm{P}<0.05$. 


\section{A-Solid}

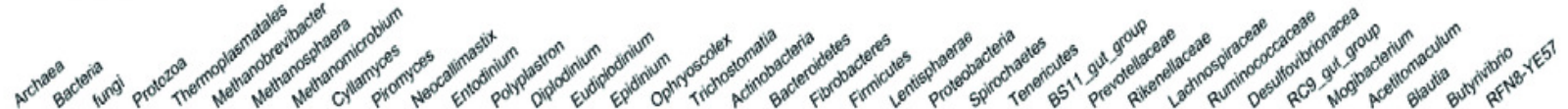

$\begin{gathered}\text { Archaea } \\ \text { Bacteria } \\ \text { fungi }\end{gathered}$ Protozoa
Pro Thermoplasmatales 39 G Methanobrevbacter 280 N

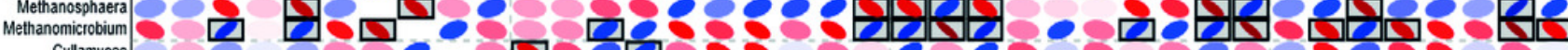
$\begin{gathered}\text { Cyllamyces } \\ \text { Piromyces }\end{gathered}$
$\begin{gathered}\text { Neocallimastix } \\ \text { Entodinium }\end{gathered}$

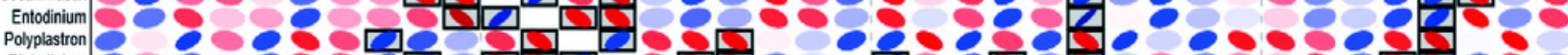
Polyplastron
Diplodinium Eudipodinim

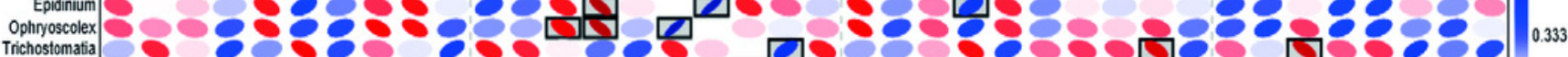
Actinobacteria $\begin{gathered}\text { Bacteridetes } \\ \text { Fibrobacteres } \\ \text { Firimicutes } \\ \text { Lentisphaerae }\end{gathered}$ , Lentisphaerae
Proteobacteria Spleobacteria
Tochetes

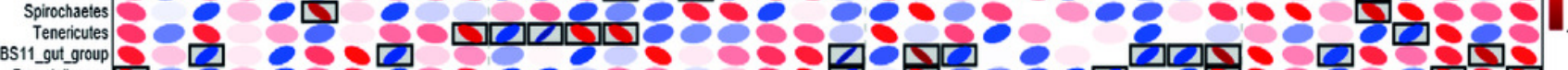
Prevotellaceae $⿴$,

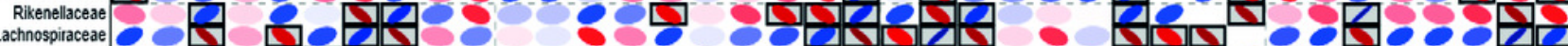
Lachnospiraceae
Puninococcaceae

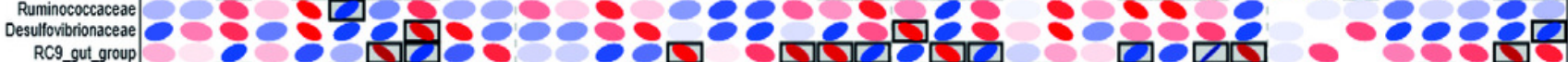
Rc9_out_group
Mogibacterium
Acetitomaculum 8 Acetitomaculum
Blautia

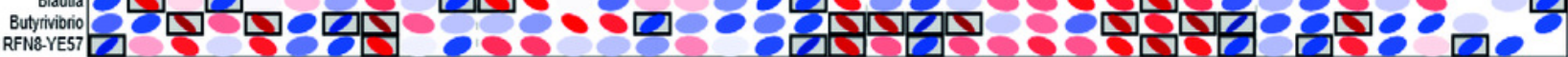

\section{B-Liquid}

Nate

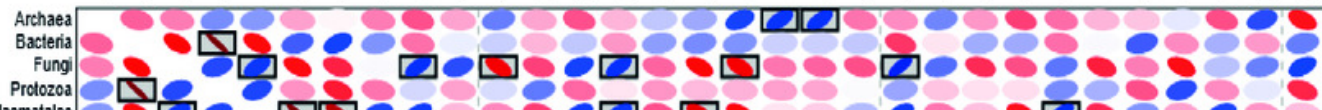

Thermoplasmatales

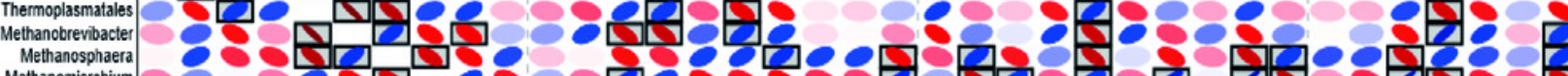

Methanosphaera
Methanomicrobium

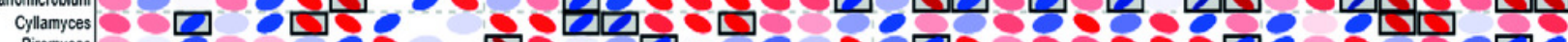
Piromyces

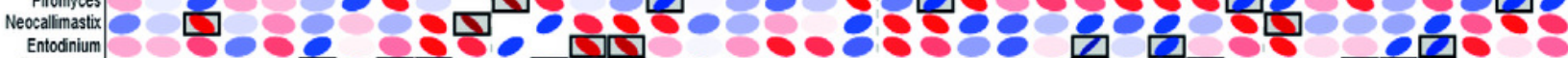
$\begin{gathered}\text { Entodinium } \\ \text { Polpylastron } \\ \text { Diplodinum }\end{gathered}$
Eudiplodinum Eudiplodinum Epianimum
Ophryoscolex Trichostomatia Iת 20 - 2 Actinobacterial
Bacteridetes , Bacteroidetes
Fibrobacteres
Fiminits

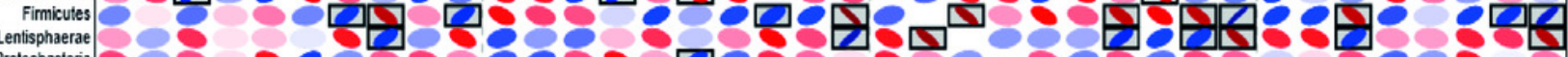

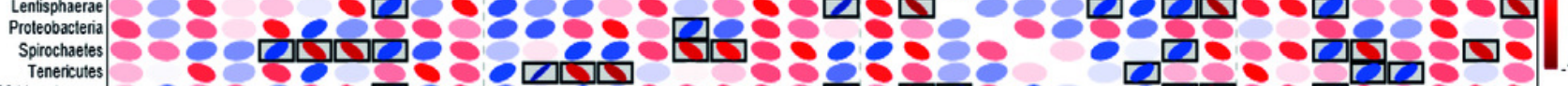

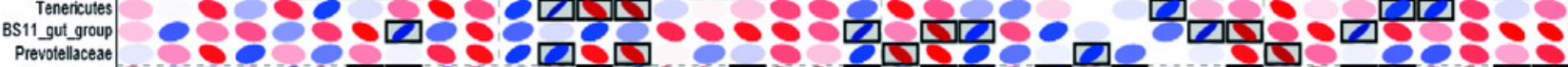

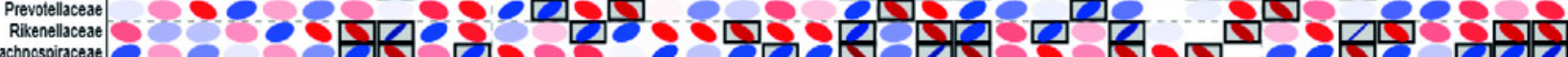
Lachnospiraceate 88 D Ruminococcaceate
Desultovibrionsease

Rc9.gut_roup 100 G Mogibacterium
Acetitomaculum

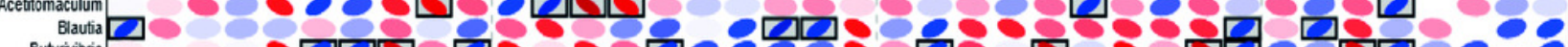
Butywibioi
RFN8.YEF? 


\section{Table $\mathbf{1}$ (on next page)}

The Relative abundance (\%) of bacteria, archaea, protozoa and fungi and diversity indices

Table 1: The Relative abundance (\%) of bacteria, archaea, protozoa and fungi and OTU numbers and values of Shannon, Chaol and Inverse Simpson indices in the ruminal solid (SF) and liquid (LF) fractions of dromedary camels fed a mixed ration (G1), high-quality forage(G2) and low-quality- forage (G3) (Mean \pm Standard error (SE)). 
1

\begin{tabular}{lllll}
\hline Item & G1 & G2 & G3 & Overall mean \\
\hline Bacteria SF & $92 \pm 1$ & $89 \pm 2$ & $89 \pm 2$ & $90 \pm 1$ \\
Bacteria LF & $85 \pm 4$ & $91 \pm 2$ & $87 \pm 8$ & $88 \pm 2$ \\
Archaea SF & $2.3 \pm 0.2$ & $3.4 \pm 0.4$ & $2.2 \pm 1.0$ & $3.0 \pm 0.3$ \\
Archaea LF & $2.2 \pm 0.2$ & $2.8 \pm 0.4$ & $1.8 \pm 0.2$ & $2 \pm 0.3$ \\
Protozoa SF & $5 \pm 1$ & $7 \pm 2$ & $6 \pm 2$ & $6 \pm 1$ \\
Protozoa LF & $12 \pm 4$ & $6 \pm 1.6$ & $8 \pm 5$ & $8 \pm 1.6$ \\
Fungi SF & $0.15 \pm 0.05$ & $1 \pm 0.3$ & $3 \pm 1$ & $1 \pm 0.4$ \\
Fungi LF & $0.35 \pm 0.1$ & $0.5 \pm 0.1$ & $3 \pm 3$ & $1 \pm 0.5$ \\
OTUs SF & $1012 \pm 43$ & $1201 \pm 38$ & $1135 \pm 148$ & $1137 \pm 39$ \\
OTUs LF & $1076 \pm 26$ & $1229 \pm 38$ & $1147 \pm 53$ & $1172 \pm 30$ \\
Shannon SF & $6 \pm 0.1$ & $7 \pm 0.10$ & $7 \pm 0.3$ & $7 \pm 0.1$ \\
Shannon LF & $6.5 \pm 0.06$ & $7 \pm 0.1$ & $7 \pm 0.1$ & $7 \pm 0.1$ \\
Chaol SF & $6644 \pm 650$ & $9329 \pm 714$ & $9028 \pm 1985$ & $8542 \pm 608$ \\
Chaol LF & $7280 \pm 521$ & $10839 \pm 724$ & $7688 \pm 625$ & $9295 \pm 672$ \\
Invsimpsone SF & $117 \pm 14$ & $863 \pm 306$ & $644 \pm 398$ & $620 \pm 196$ \\
Invsimpsone LF & $135 \pm 21$ & $983 \pm 492$ & $612 \pm 142$ & $684 \pm 282$ \\
\hline
\end{tabular}

2

3 


\section{Table 2 (on next page)}

Relative abundance (\%) of bacterial phyla

Table 2: Relative abundance (\%) of bacterial phyla in the ruminal solid (SF) and liquid (LF) fractions of camels fed a mixed ration(G1), high-quality forage(G2) and low-quality forage (G3) (Mean \pm Standard Error (SE)). 


\begin{tabular}{lllll}
\hline Bacterial Phylum & G1 & G2 & G3 & Overall mean \\
\hline Firmicutes SF & $63 \pm 2$ & $65 \pm 0.1$ & $48 \pm 10$ & $60 \pm 3$ \\
Firmicutes LF & $46 \pm 3$ & $56 \pm 2$ & $45 \pm 13$ & $50 \pm 3$ \\
Bacteroidetes SF & $20 \pm 1$ & $15 \pm 1$ & $27 \pm 8$ & $19 \pm 2$ \\
Bacteroidetes LF & $31 \pm 0.5$ & $21 \pm 1.5$ & $31 \pm 12$ & $26 \pm 3$ \\
Proteobacteria SF & $5 \pm 1$ & $3.5 \pm 0.3$ & $3 \pm 0.5$ & $4 \pm 0.3$ \\
Proteobacteria LF & $6.5 \pm 1$ & $6 \pm 2$ & $3 \pm 0.1$ & $5.5 \pm 1$ \\
Spirochaetes SF & $3 \pm 0.6$ & $5 \pm 1$ & $6 \pm 1.5$ & $4.5 \pm 0.6$ \\
Spirochaetes LF & $3.7 \pm 1$ & $2.6 \pm 0.5$ & $5.6 \pm 1$ & $3.5 \pm 0.5$ \\
Fibrobacteres SF & $2.5 \pm 0.6$ & $4 \pm 0.7$ & $9 \pm 1$ & $4.5 \pm 1$ \\
Fibrobacteres LF & $1.6 \pm 0.5$ & $2.5 \pm 1$ & $7 \pm 3$ & $3 \pm 1$ \\
Actinobacteria SF & $2 \pm 0.2$ & $4.5 \pm 0.3$ & $1.5 \pm 0.3$ & $3 \pm 0.5$ \\
Actinobacteria LF & $1.5 \pm 0.14$ & $5.5 \pm 1$ & $1 \pm 0.1$ & $3.6 \pm 1$ \\
Lentisphaerae SF & $0.7 \pm 0.03$ & $0.7 \pm 0.1$ & $1.5 \pm 0.2$ & $1 \pm 0.1$ \\
Lentisphaerae LF & $3.2 \pm 0.3$ & $2 \pm 0.5$ & $3.2 \pm 2$ & $2.6 \pm 0.4$ \\
Tenericutes SF & $2 \pm 0.4$ & $1 \pm 0.1$ & $0.6 \pm 0.3$ & $1 \pm 0.2$ \\
Tenericutes LF & $3.7 \pm 0.6$ & $1.5 \pm 0.3$ & $0.4 \pm 0.1$ & $1.8 \pm 0.4$ \\
Verrucomicrobia SF & $0.3 \pm 0.1$ & $0.20 \pm 0.1$ & $0.6 \pm 0.4$ & $0.30 \pm 0.1$ \\
Verrucomicrobia LF & $2.2 \pm 0.4$ & $1 \pm 0.3$ & $1.3 \pm 0.3$ & $1.3 \pm 0.3$ \\
Chloroflexi SF & $0.4 \pm 0.03$ & $0.5 \pm 0.06$ & $0.24^{\mathrm{a}}$ & $0.4 \pm 0.04$ \\
Chloroflexi LF & $0.3 \pm 0.03$ & $0.3 \pm 0.05$ & $0.24^{\mathrm{a}}$ & $0.3 \pm 0.02$ \\
Cyanobacteria SF & $0.3 \pm 0.04$ & $0.3 \pm 0.05$ & $0.5^{\mathrm{a}}$ & $0.35 \pm 0.04$ \\
Cyanobacteria LF & $0.3 \pm 0.05$ & $0.3 \pm 0.05$ & $0.25^{\mathrm{a}}$ & $0.3 \pm 0.03$ \\
Elusimicrobia SF & $0.2 \pm 0.05$ & 0.15 & $0.3 \pm 0.14$ & $0.2 \pm 0.04$ \\
Elusimicrobia LF & $0.3 \pm 0.07$ & $0.2 \pm 0.04$ & $0.8 \pm 0.4$ & $0.4 \pm 0.1$ \\
\hline
\end{tabular}

a The value was calculated from one animal. 


\section{Table 3(on next page)}

Relative abundance (\%) of archaeal orders and genera

Table 3: Relative abundance (\%) of archaeal orders and genera observed in the ruminal solid (SF), and liquid (LF) fractions of camels under different feeding systems. Animals in G1 fed a mixed ration, animal in G2 fed high-quality forage and animal in G3 fed low qualityforage (Mean \pm Standard Error (SE)). 
1

2

\begin{tabular}{lllll}
\hline Archaea & G1 & G2 & G3 & Overall mean \\
\hline Thermoplasmatales SF & $33 \pm 7$ & $33 \pm 4$ & $55 \pm 10$ & $37 \pm 4$ \\
Thermoplasmatales LF & $46 \pm 8$ & $48 \pm 3$ & $67 \pm 5$ & $51 \pm 3$ \\
Methanomicrobium SF & $1 \pm 0.3$ & $0.3 \pm 0.2$ & $8 \pm 1$ & $2 \pm 0.9$ \\
Methanomicrobium LF & $2 \pm 0.5$ & $1 \pm 0.5$ & $9 \pm 6$ & $3 \pm 1$ \\
Methanobrevibacter SF & $51 \pm 5$ & $42 \pm 3$ & $34 \pm 9$ & $43 \pm 3$ \\
Methanobrevibacter LF & $43 \pm 5$ & $39 \pm 2.4$ & $23 \pm 0.01$ & $37 \pm 2$ \\
Methanosphaera SF & $15 \pm 2$ & $24 \pm 3$ & $3 \pm 1$ & $18 \pm 3$ \\
Methanosphaera LF & $8 \pm 2$ & $12 \pm 1.5$ & $2.5 \pm 1$ & $9.5 \pm 1.5$ \\
Methanobacterium SF & 0.05 & 0.06 & 0 & ND \\
Methanobacterium LF & $0.2 \pm 0.02$ & $0.1 \pm 0.02$ & 0 & ND \\
\hline
\end{tabular}

ND: Non Determined

4 


\section{Table 4(on next page)}

Relative abundance (\%) of protozoal genera

Table 4: Relative abundance (\%) of protozoal genera in the ruminal solid (SF) and liquid fraction (LF) of camels under different feeding systems. Animals in G1 fed a mixed ration, animals in G2 fed high-quality forage and animals in G3 fed low-quality forage (Mean $\pm \mathrm{SE}$ ). 
1

\begin{tabular}{lcccc}
\hline Protozoa & G1 & G2 & G3 & Overall mean \\
\hline Entodinium SF & $23 \pm 6$ & $6.5 \pm 0.6$ & $6 \pm 1$ & $11 \pm 3$ \\
Entodinium LF & $54 \pm 10$ & $15 \pm 2.5$ & $5 \pm 1$ & $24 \pm 6$ \\
Polyplastron S F & $10 \pm 1$ & $17.5 \pm 2$ & $25 \pm 3$ & $17 \pm 2$ \\
Polyplastron LF & $6 \pm 1$ & $11 \pm 0.2$ & $24 \pm 3$ & $12 \pm 2$ \\
Diplodinium S F & $23 \pm 1$ & $35 \pm 3$ & $49 \pm 10$ & $34 \pm 3$ \\
Diplodinium LF & $13 \pm 3$ & $27 \pm 3$ & $61 \pm 6$ & $29 \pm 5$ \\
Eudiplodinium SF & $8 \pm 0.6$ & $8 \pm 2$ & $2 \pm 0.7$ & $7 \pm 1$ \\
Eudiplodinium LF & $4 \pm 1$ & $5.5 \pm 1$ & $2.5 \pm 0.5$ & $4.5 \pm 0.6$ \\
Epidinium SF & $5 \pm 0.8$ & $4 \pm 1$ & $2 \pm 1$ & $4 \pm 0.1$ \\
Epidinium LF & $3 \pm 0.8$ & $4.5 \pm 0.6$ & $1 \pm 0.7$ & $3.5 \pm 0.5$ \\
Ophryoscolex SF & $30 \pm 4$ & $27 \pm 3$ & $15 \pm 5$ & $26 \pm 2.5$ \\
Ophryoscolex LF & $19 \pm 4$ & $29 \pm 0.6$ & $6.5 \pm 4$ & $22 \pm 3$ \\
Trichostomatia SF & $0.1 \pm 0.02$ & $1 \pm 0.25$ & $0.3 \pm 0.15$ & $1 \pm 0.2$ \\
Trichostomatia LF & $0.2 \pm 0.04$ & $1 \pm 0.2$ & $1 \pm 0.1$ & $1 \pm 0.2$ \\
Isotricha SF & $0.2 \pm 0.04$ & $0.3 \pm 0.05$ & $0.3 \pm 0.004$ & $0.3 \pm 0.03$ \\
Isotricha LF & $0.5 \pm 0.2$ & $2 \pm 0.9$ & $0.3 \pm 0.01$ & $1 \pm 0.5$ \\
Dasytricha SF & $0.04 \pm 0.01$ & $1.5 \pm 0.3$ & $0.2 \pm 0.15$ & $1 \pm 0.3$ \\
Dasytricha LF & $0.1 \pm 0.002$ & $5.5 \pm 0.8$ & $0.5 \pm 0.3$ & $3 \pm 1$ \\
\hline
\end{tabular}




\section{Table 5 (on next page)}

Relative abundance (\%) of fungal genera

Table 5: Relative abundance (\%) of fungal genera in the ruminal solid (SF) and liquid fraction (LF) of camels under different feeding systems. Camels in G1 fed a mixed ration, animals in G2 fed high- quality forage, and animals in G3 fed low- quality forage (Mean $\pm \mathrm{SE}$ ). 
1

\begin{tabular}{lcccc}
\hline Fungi & G1 & G2 & G3 & Overall mean \\
\hline Spizellomyces SF & 0 & 0.1 & 0.02 & ND \\
Spizellomyces LF & $0.3 \pm 0.1$ & $0.3 \pm 0.1$ & 0 & ND \\
Cyllamyces SF & $2 \pm 0.6$ & $3 \pm 1.5$ & $7 \pm 4$ & $3.5 \pm 1$ \\
Cyllamyces LF & $2 \pm 0.8$ & $3 \pm 0.8$ & $10 \pm 1$ & $4 \pm 1$ \\
Piromyces SF & $6 \pm 3$ & $12 \pm 0.7$ & $8 \pm 1$ & $9 \pm 1$ \\
Piromyces LF & $6 \pm 4$ & $12 \pm 2$ & $10 \pm 6$ & $10 \pm 2$ \\
Neocallimastix SF & $92 \pm 3$ & $85 \pm 1$ & $85 \pm 3$ & $87 \pm 1$ \\
Neocallimastix LF & $92 \pm 4$ & $85 \pm 1.5$ & $81 \pm 7$ & $86 \pm 2$ \\
\hline
\end{tabular}

2 ND: Non Determined 